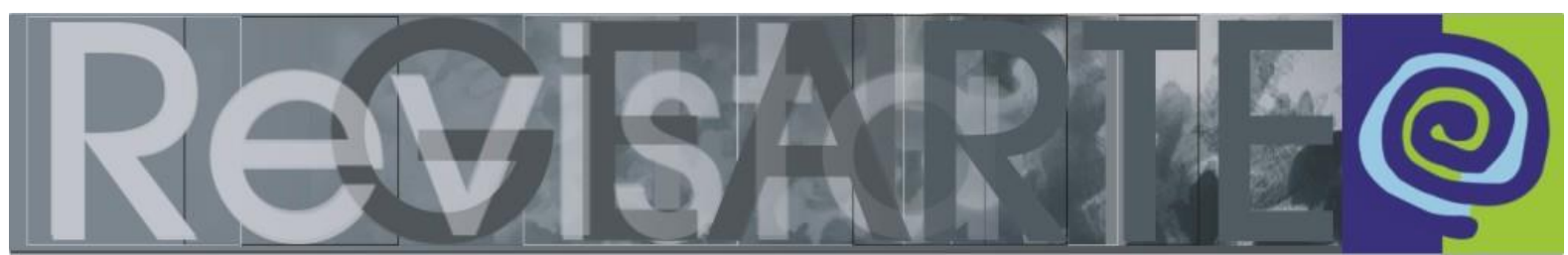

ISSN 2357-9854

\title{
Artes Visuais em um espaço não formal de educação: uma mostra e uma experiência de mediação como interface público/arte
}

\author{
Airton Jordani Jardim Filho (Universidade Estadual de Santa Catarina - UDESC, \\ Florianópolis/SC, Brasil)
}

\begin{abstract}
RESUMO - Artes Visuais em um espaço não formal de educação: uma mostra e uma experiência de mediação como interface público/arte $-O$ presente artigo objetiva discutir a mostra [ gaveta(s) ], proposta, elaborada e produzida durante a disciplina de Ação Educativa em Espaços Culturais, do Programa de Pós-Graduação em Artes Visuais do Centro de Artes da Universidade do Estado de Santa Catarina (PPGAV/CEART/UDESC), que apresentava a gaveta como metáfora da memória. Compreendendo que a mediação não deve ser a única atribuição dos educadores atuantes nesses espaços e, tendo por base as referências teóricas discutidas em sala de aula, os alunos da disciplina, ao projetar e colocar em prática uma mostra de trabalhos artísticos, puderam participar de todas as etapas de uma exposição, desde a concepção inicial até sua divulgação. Nesse sentido, o texto apresenta os desdobramentos da experiência de mediação realizada durante a exposição. Além disso, a reflexão presente nesse artigo busca posicionar conceitualmente a mediação como interface interativa, a partir da proposição de Grossmann (2011).
\end{abstract}

PALAVRAS-CHAVE

Gavetas. Memória. Ação Educativa. Exposição.

ABSTRACT - Visual arts in a non formal educational space: an exhibition and the experience of mediation as interface audience/art - This paper aims to discuss the exhibition [ gaveta(s) ] proposed, developed and produced during Education Action in Cultural Spaces subject of the Postgraduate Program in Visual Arts, Center of Art, State University of Santa Catarina Program (PPGAV / CEART / UDESC), and had the drawer as a metaphor for memory. It's possible to say that mediation should not be the only assignment of educative action on cultural institution. Based on the theoretical references discussed in the classroom, the students were able to design and produce an exhibition, participating of all stages of this kind of production, from initial conception until disclosure. It's presented, also, the pratical aplication on a mediation experience which happened during the exhibition period. Additionally, the present article intends to locate conceptually mediation as an interactive interface, based on Grossmann's proposition (2011).

KEYWORDS

Drawers. Memory. Education Actions. Exhibition.

\section{Uma disciplina acadêmica e sua potência educacional}

Em junho de 2016 ocorreu, no Museu da Escola Catarinense (MESC), a mostra chamada [ gaveta(s) ], componente curricular da disciplina Ações Educativas em Espaços Culturais, do Programa de Pós-Graduação em Artes Visuais (PPGAV), do Centro de Artes (CEART), da Universidade do Estado de Santa Catarina (UDESC). $O$ objetivo era construir, dentro da disciplina, uma exposição que pudesse servir de 
laboratório para se colocar em prática os conceitos e os debates decorrentes do percurso da turma, durante o semestre, em sala de aula, acerca da Ação Educativa. Em suma, a mostra propiciaria aos alunos uma prática articulada à teoria.

Ministrada no primeiro semestre de 2016, a disciplina faz parte da grade curricular do programa de Pós-Graduação em Artes Visuais (PPGAV). Conforme o plano de ensino da disciplina, sua ementa ${ }^{1}$ engloba

\begin{abstract}
Concepções de museus e de espaços expositivos contemporâneos. Crise nos museus. Espaços culturais e ação educativa: de guia a educador. Diferentes propostas de ação educativa: teorias e práticas. Novas tendências de ação educacional na contemporaneidade. Material pedagógico para ação educativa. O público: os públicos e os públicos especiais. Planejamento da Ação Educativa.
\end{abstract}

Ainda segundo o plano de ensino, ela teve como objetivo geral "Vivenciar experiências de observação e atuação em espaços culturais, subsidiadas por planejamento, estudos teóricos e experiências de mediação, na perspectiva de concebê-los como lócus privilegiado para a construção de conhecimentos". A partir de seu objetivo geral, pode-se compreender a proposta docente de concepção, na íntegra, por parte do grupo, de uma mostra, e sua consequente ação educativa, realizando uma mediação concebida dentro desse contexto, ou seja, de priorização da ação educativa para o evento. Isto quer dizer que os trabalhos apresentados também deveriam propiciar a interação com o público, para que a mediação pudesse cumprir de forma plena sua função de interface entre arte e público.

Antes de se aprofundar às questões relativas à exposição e à experiência prática que ela propiciou, é necessário balizar conceitos básicos referentes ao que este artigo trata como interação e interface e sua relação com a mediação.

\title{
Interação, interface e mediação
}

A origem da ligação da palavra interação com as novas tecnologias remonta o ano de 1962, e foi apresentada por Ivan Sutherland, em sua tese de doutorado, defendida no Massachusetts Institute of Technology (MIT). O pesquisador criou um

1 Conforme consta no Plano de Ensino da disciplina Ação Educativa em Espaços Culturais, do Programa de Pós-Graduação em Artes Visuais. 
equipamento chamado de "Sketchpad", em que o usuário desenhava sobre uma tela, com uma caneta especial, podendo visualizar, quase que instantaneamente, as figuras geométricas que gerava (FRANCO, 2004).

Fleming, que já registrava em seus escritos pesquisas sobre as interfaces no final dos anos 1990, definia interação como duas ou mais pessoas realizando uma troca. Ainda segundo a autora, "no computador, a interação continua sendo duas ou mais pessoas realizando uma troca, mas neste caso, a interação é mediada pela tecnologia" (FLEMING, 1998, p. 73).

Por mais que o senso comum trate interação como sendo uma palavra do domínio da informática, ao analisar as mais diferentes definições para esta palavra, é possível constatar que sua existência não está ligada apenas à presença de uma interface computacional. Filatro (2007, p. 125), pedagoga e pesquisadora na área do design instrucional, define interação como sendo o "comportamento das pessoas em relação à outra(s) pessoa(s) e a sistemas; ação recíproca pela qual os indivíduos e objetos se influenciam mutuamente".

Se a interação é uma ação recíproca entre duas ou mais pessoas ou objetos, mediados por uma interface que possibilite comunicação entre ambos em sua plenitude, a arte interativa, por consequência, pode existir igualmente sem a presença de computadores. Para tanto, o que interessa, de fato, é que exista a ação recíproca entre entes do sistema que compõe a relação.

Quando se fala em ação recíproca entre entes do sistema, é importante lembrar que em muitos desses casos, para que as partes que buscam interagir tenham sucesso nessa tarefa, às vezes se faz necessária a existência de uma interface que articule a mediação entre as partes. Interface é um conceito que está presente no dia a dia de todas as pessoas, porém nem sempre é entendida em suas diversas dimensões. O senso comum muitas vezes relaciona interface a dispositivos eletrônicos - sejam eles smartphones, tablets, notebooks, entre outros. No entanto, a interface está presente em dispositivos comunicacionais de qualquer natureza, inclusive produtos não digitais. Segundo uma definição genérica, interface pode ser considerada uma superfície que delimita dois corpos, espaços ou fases. Também 
pode ser vista como um dispositivo, físico ou lógico, responsável pela adaptação entre dois sistemas independentes.

Uma palavra-chave no que tange à interface é mediação. A interface permite, promove, regula e media processos que podem ser ou não relacionais atuando, quando necessário, como tradutor entre esses processos, como forma de permitir que ambos comuniquem-se entre si, através do entendimento e da habilidade em responder corretamente aquilo que o seu interlocutor pergunta e vice-versa (GROSSMANN, 2011, p. 217).

Levy (1993, p. 181), ao tratar deste tema, afirma que

[...] a noção de interface pode estender-se ainda para além do domínio dos artefatos. Esta é, por sinal, sua vocação, já que interface é uma superfície de contato, de tradução, de articulação entre dois espaços, duas espécies, duas ordens de realidade diferentes: de um código para outro, do analógico para o digital, do mecânico para o humano... Tudo aquilo que é tradução, transformação, passagem, é da ordem da interface.

Nem sempre as duas partes - ou sistemas - envolvidos nesse processo de comunicação se expressam através da mesma maneira. Expressar-se da mesma maneira, neste caso, reforça a questão de que, se há dois ou mais sistemas diferentes interagindo, essa interação trata-se de um processo de comunicação, em que mensagens entre as partes são trocadas e, possivelmente, cada parte codificando as mensagens emitidas à sua própria maneira, nem sempre compreensíveis pelas demais partes. Daí a relação direta com a tradução, ou seja, para que a outra parte de um diálogo possa entender sua mensagem, muitas vezes é necessário que aquilo que foi dito em uma linguagem que se domina seja traduzido para a linguagem da outra parte, pois ela pode não dominar a linguagem do outro.

Apesar de ser um conceito polissêmico utilizado em diversas áreas do conhecimento, com diferentes significados, variando conforme o uso que dele se faz, o conceito do qual o senso comum se apropriou é muito próximo àquele utilizado pelos estudiosos e profissionais da computação e ratificado na definição de uma obra de referência. Ao buscar a definição de interface em dicionários, encontra-se como primeira opção de definição um conceito criado sob o ponto de vista da informática possivelmente por tratar-se de seu uso mais comum, nos dias atuais. Assim, a palavra interface aparece definida como um "dispositivo (material e lógico) graças ao qual se efetuam as trocas de informações entre dois sistemas". Além disso, outras definições 
podem ser encontradas: em um contexto didático, trata-se do "limite comum a dois sistemas ou duas unidades que permite troca de informações". Por extensão, pode referir-se, ainda, a um "interlocutor privilegiado entre dois serviços, duas empresas, etc." (PRIBERAM).

Assim como no caso da interação, é bastante comum o uso da palavra interface diretamente relacionado a computadores, como se antes de sua popularização, não houvesse interfaces. Johnson, pioneiro teórico das interfaces digitais, ao tratar de interfaces, questiona: "Mas, afinal, que é exatamente uma interface? Em seu sentido mais simples, a palavra se refere a softwares que dão forma à interação entre usuário e computador" (JOHNSON, 2001, p. 17). Ainda que influenciado pelo senso comum sobre um conceito de interfaces ligado a computadores, Johnson já buscava ir além. Segundo o autor, a interface atua como uma espécie de tradutor, mediando entre duas partes, tornando uma sensível para outra (Idem), em um conceito próximo ao apresentado por Levy (1993). Bonsiepe (1997, p. 12), ao definir interface lembra que "a interface transforma sinais em informação interpretável. A interface transforma simples presença física em disponibilidade".

Retomando as ideias de Grossmann (2011), Levy (1993) e Filatro (2007) é bastante apropriado que se conceba a ação educativa como uma interface entre o trabalho artístico e o público, ambos configurados como entes de um sistema que, neste caso, promove a interação de tais entes. É a ação educativa, através da mediação, que dá forma a essa interação, tomando emprestada a expressão de Johnson (2001).

\section{A mostra [ gaveta(s) ]}

Durante a disciplina Ação Educativa em Espaços Culturais, um dos tópicos mais presentes foi a relação com a estrutura envolvida para a produção de mostras e exposições, dentro de museus, galerias e outros tantos espaços expositivos. Era consenso entre os alunos a posição defendida pela professora da disciplina de "que a mediação não deve ser a única atribuição afeta aos educadores desses espaços" (RAMALHO E OLIVEIRA, 2016). Assim, engajados em um projeto surgido na 
disciplina e proposto pela professora, os alunos puderam vivenciar todas as etapas de uma exposição, "desde a ideia inicial das mostras até sua divulgação" (Idem).



Fonte: arquivo dos autores.

A mostra contou com obras dos alunos da disciplina (em ordem alfabética): Airton Jordani, Ana Sabiá, Denilson Antonio, Fábio Wosniak, Josy Souza, Luciano Buchmann, Maressa Macedo, Mayra Flaminio, Neusa Duarte, Tatiana Cobucci, bem como a professora da disciplina. Segundo ela, conforme o texto de parede:

O que se pode observar é que se trata de um grupo formado por pessoas com passado, trajetórias e intencionalidades distintas, o que redunda em conceitos diferentes de memória, além dos diversos modos de abordar a temática. É o que o (s) do plural de gaveta bem o anuncia. (RAMALHO E OLIVEIRA, 2016).

Os trabalhos desenvolvidos para a exposição tinham por base a gaveta como metáfora para a memória. Ou, em outras palavras, a memória foi o objeto teórico, e 
a(s) gaveta(s), o objeto empírico. Um dos autores da base teórica, escolhido como lastro para as discussões sobre memória durante a concepção da exposição, foi o livro "Seduzidos pela Memória", de Andreas Huyssen (2000). A obra é uma coletânea de ensaios sobre o que o autor denomina de cultura pós-moderna e aborda uma possível reação da sociedade contemporânea à globalização, através da idealização das tradições, o que colocaria no foco principal desta mesma sociedade, a questão da memória.

Quanto mais o capitalismo de consumo avançado prevalece sobre o passado e o futuro, sugando-os num espaço sincrônico em expansão, menor a estabilidade ou a identidade que proporciona aos assuntos contemporâneos. (HUYSSEN, 2000, p. 29).

Há, desde a queda do muro de Berlim, do final das ditaduras latino-americanas e do apartheid na África do Sul, um crescimento desenfreado de fenômenos como a globalização e o capitalismo de consumo avançado. Tais fenômenos geram tempos de incertezas, angústias e baixa autoestima nas sociedades ocidentais. A resposta a este avanço, segundo Huyssen (2000) é a emergência da memória como uma das preocupações culturais e políticas centrais destas sociedades segundo o autor,

\footnotetext{
Precisa-se da memória e da musealização juntas para construir uma proteção contra a obsolescência e o desaparecimento, para combater a nossa profunda ansiedade com a velocidade de mudança e o contínuo encolhimento dos horizontes de tempo e de espaço. (HUYSSEN, 2000, p. 28).
}

Ou seja, a opção da maioria dos alunos da turma pelo tema "memória" não é uma coincidência. A constatação aproxima-se do que Argan (1994, p. 19) afirma, ao refutar a idéia de que a obra de arte é um reflexo do momento vivido pela sociedade. A arte se insere "não como um reflexo, mas como agente" no contexto histórico. Ela não só é oriunda, como este contexto também é fruto da própria obra. Ambos estão a fazer-se, ao mesmo tempo, o tempo todo, em um processo dialético.

Ciente destas questões acerca da memória e da sua relação sócio-histórica com a realidade é que foi pensada a proposta de mediação que foi desenvolvida com um grupo específico, escolhido pelo autor, para pôr em prática alguns preceitos da disciplina. A proposta inicial era baseada em dois momentos em que se partiria de uma realidade particular, individual e personalizada para o seu contexto social e 
histórico, inserido na sociedade ocidental contemporânea, utilizando-se para isso a mediação como uma interface entre a proposta articulada em sala de aula e a realidade dos visitantes da mostra.

\section{Mediando a mostra [ gaveta(s) ]: ação educativa na prática}

O grupo escolhido para a experiência de mediação, pelo autor, era formado por membros da família, uma vez que o trabalho apresentado tinha como fio condutor memórias familiares, a partir da escolha e manipulação digital de fotos do acervo pessoal. Faziam parte do grupo membros da família deste autor: Susana (mãe, 63 anos), Eduarda (sobrinha/afilhada, 17 anos), Greicy (esposa, 36 anos) e Antonio (filho, sete anos).

A proposta de mediação desenvolvida para este grupo foi calcada em dois momentos distintos: em um primeiro momento, apropriando-se - através de sondagem realizada na parte inicial da conversa - do repertório e da experiência prévia dos visitantes e, um segundo momento, a partir de Huyssen (2000), discutindo memória como uma manifestação social, com características comuns dentro de um processo vivenciado pela sociedade ocidental neste período compreendido entre a queda do muro de Berlim e os dias de hoje.

A sondagem foi realizada durante a chegada ao espaço expositivo. Foi solicitado ao grupo que comentasse como poderia se dar a relação entre gavetas e memórias. A exceção de Antonio, de sete anos, os demais membros do grupo tinham ideias bastante claras de como essa relação poderia se dar e, ainda, de como a gaveta poder ser utilizada como uma metáfora para a memória.

O passo seguinte foi pedir ao grupo que fizesse uma breve visita à exposição. Neste momento, foi possível ao mediador observar a reação natural de cada um dos membros do grupo frente às várias obras e, ainda, perceber quais foram os trabalhos que geraram mais inquietações.

A seguir, foi realizado um trajeto que incluiu as obras de maior interesse de modo a deixar para o final o trabalho "Fundo da gaveta, fundo da memória". Os trabalhos comentados foram: "De cabeça em cabeça" (de Denilson Antonio), "Lembrar 
é existir" (de Tatiana Cobucci), sem título (de Sandra Ramalho) e "Memória subterrânea" (de Luciano Buchmann). Uma breve parada em frente a cada uma das obras permitiu, ao menos, uma breve conversa sobre cada um dos trabalhos, com os visitantes deixando suas impressões sobre eles e tendo liberdade para eventuais perguntas que gostariam de fazer.

Figura 2 - Denílson Antonio, De cabeça em cabeça, 2016

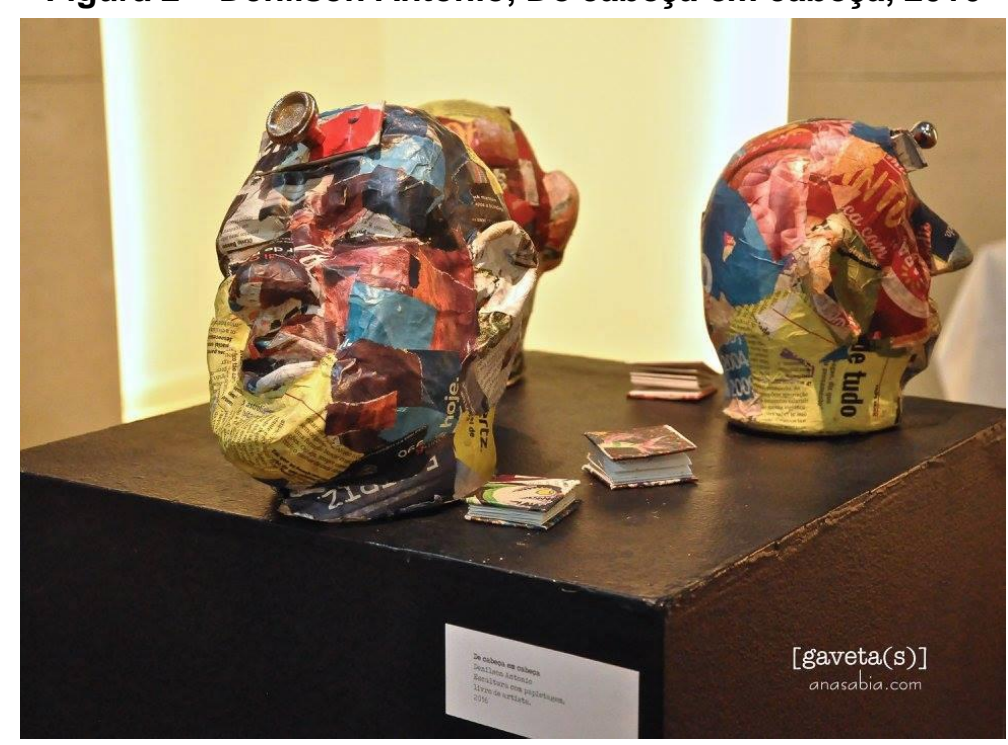

Fonte: anasabia.com.

A interatividade proposta pelo trabalho de Denilson fez com que o grupo se detivesse bastante neste trabalho, a ponto de ter sido necessário convidá-los a ir adiante. As gavetas colocadas na testa das cabeças, guardando memórias em formato de minilivros, propiciaram que Antonio entendesse melhor a metáfora que, no início, não havia ficado clara. Greicy fez questão de interagir com a obra, deixando seu registro por escrito, em um dos minilivros. 
Figura 3 - Tatiana Cobucci, Lembrar é existir, 2016

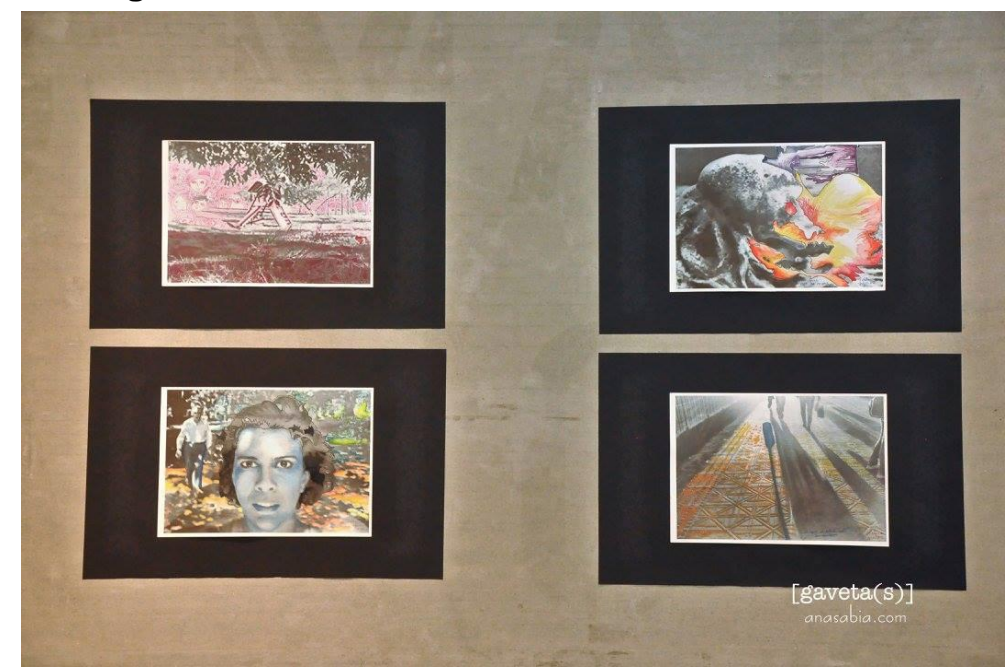

Fonte: anasabia.com.

A obra de Tatiana Cobucci, por sua vez, suscitou discussão a respeito de memórias e sonhos no grupo, pois Eduarda acreditava que não seriam ilustrações de memórias, mas representações de sonhos. Greicy e Susana argumentaram que fazia parte da temática, afinal "os sonhos são uma espécie de memória", assim como nos trabalhos de Neusa Duarte. O trabalho de Sandra Ramalho possibilitou explicar outro tipo de memória, principalmente a Antonio: vestígios como uma possibilidade de memória, assim como no caso dos sonhos. Ele havia achado estranho que a mesa não tinha "nenhuma comida", apenas os "papeizinhos". A partir de exemplos similares de vestígios (como uma forma de memória, como uma casa em ruínas ou um cartaz velho e deteriorado colado em um muro), o conceito ficou mais claro. 


\section{Figura 4 - Sandra Ramalho e Oliveira, Sem título, 2016}

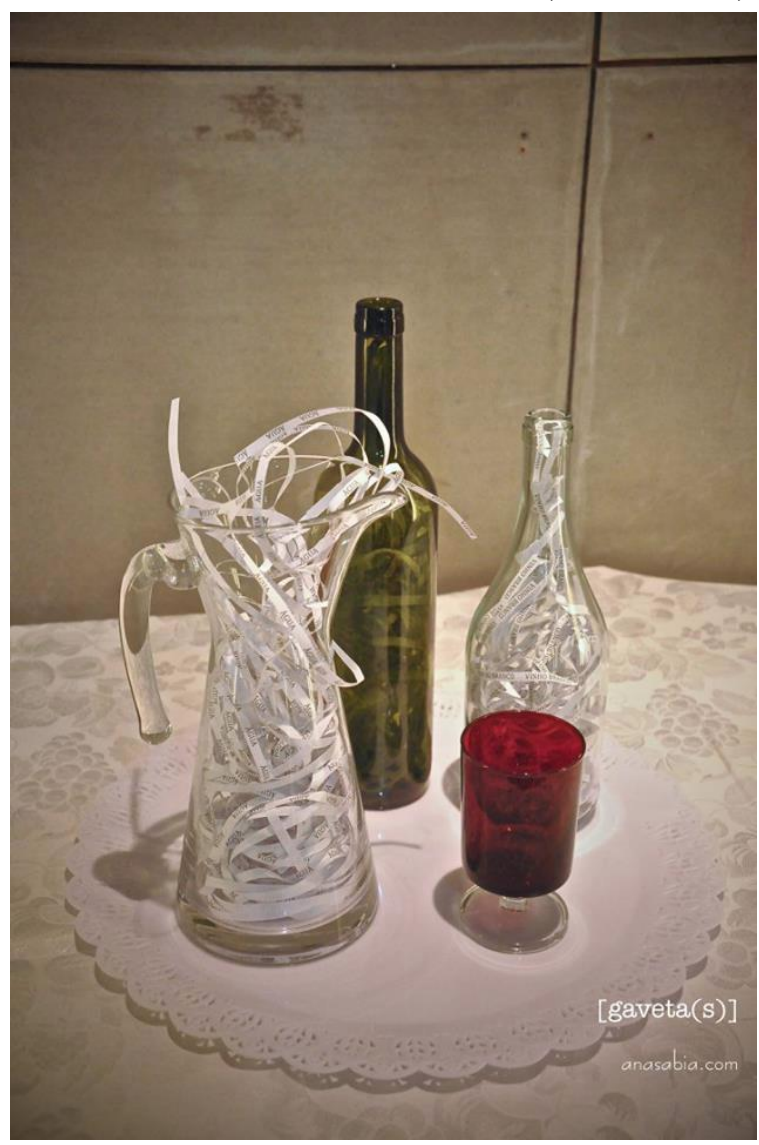

Fonte: anasabia.com.

A conversa sobre a obra de Luciano Buchmann complementou o diálogo a respeito dos vestígios como possibilidade de memória, iniciado na observação do trabalho de Sandra Ramalho. Antonio não conhecia o papel carbono; Susana, por sua vez, disse que trazia à memória os muitos anos de serviço público e sua burocracia peculiar. Greicy lembrou das matrizes para mimeógrafo na escola. Estas observações possibilitaram apontar este outro lado da exposição: os objetos ali expostos também possibilitavam o resgate de memórias e afetos próprios de cada um. Como escreveu a professora Rosângela Cherem, no livro de visitas da exposição: "SandraRa (sic) e demais: adorei os objetos, cheios de sensibilidade e afeto. Parabéns!". 


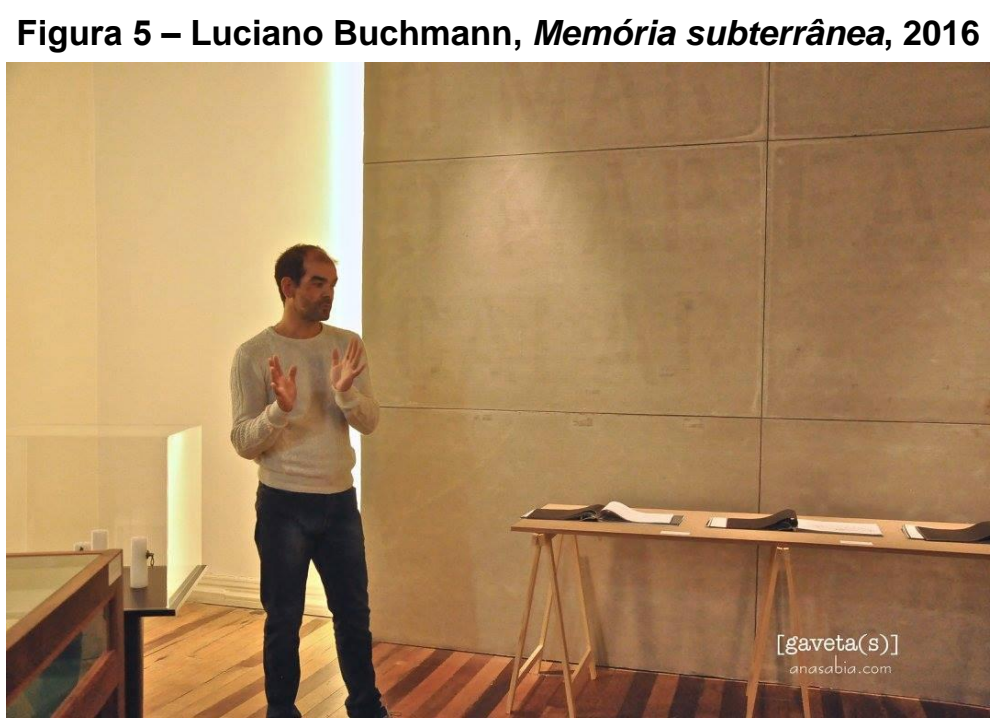

Fonte: anasabia.com.

A última obra visitada foi, deliberadamente, "Fundo da gaveta, fundo da memória”. Levando em conta o público em questão, o diálogo da mediação foi focado na questão da volatividade da memória, do contraponto entre perto e longe e cima e baixo (no tempo e no espaço). Tendo em vista que a obra consistia em gavetas que serviam de molduras para cartemas ${ }^{2}$, um aspecto relevante era a diferença de visualização estando próximo ou distante do trabalho, bem como a metáfora da memória de algo recente e de algo distante, temporalmente falando. Greicy observou que "se a gente fica mais atrás, fecha os olhos por segundos e depois abre as memórias todas se misturam, e precisaria de um tempinho pra reorganizá-las, ou se pode deixar tudo misturado".

Outro ponto explorado no diálogo de mediação foi a respeito da posição das gavetas na parede: "a posição e o material de que eram feitas as gavetas eram relevantes para a leitura da obra e por quê?". Susana apontou que "essa foi a primeira coisa a chamar a atenção, pois eram muito diferentes os materiais e claramente havia a indicação de que a gaveta mais antiga estava acima", até porque ela conhecia todas as pessoas presentes na fotografia e sabia que a gaveta mais acima emoldurava um trabalho feito a partir de uma fotografia de seu pai, já falecido, assim como a gaveta mais abaixo emoldurava uma foto de seu neto, Antonio. Já Greicy leu a obra como

2 Neologismo criado pelo filólogo Antônio Houaiss, a palavra cartema designa uma composição visual construída a partir de várias cópias de determinada imagem, tendo como suporte a técnica da colagem. 
uma árvore genealógica, onde o parentesco chamou mais a atenção do que a linha de tempo propriamente dita.

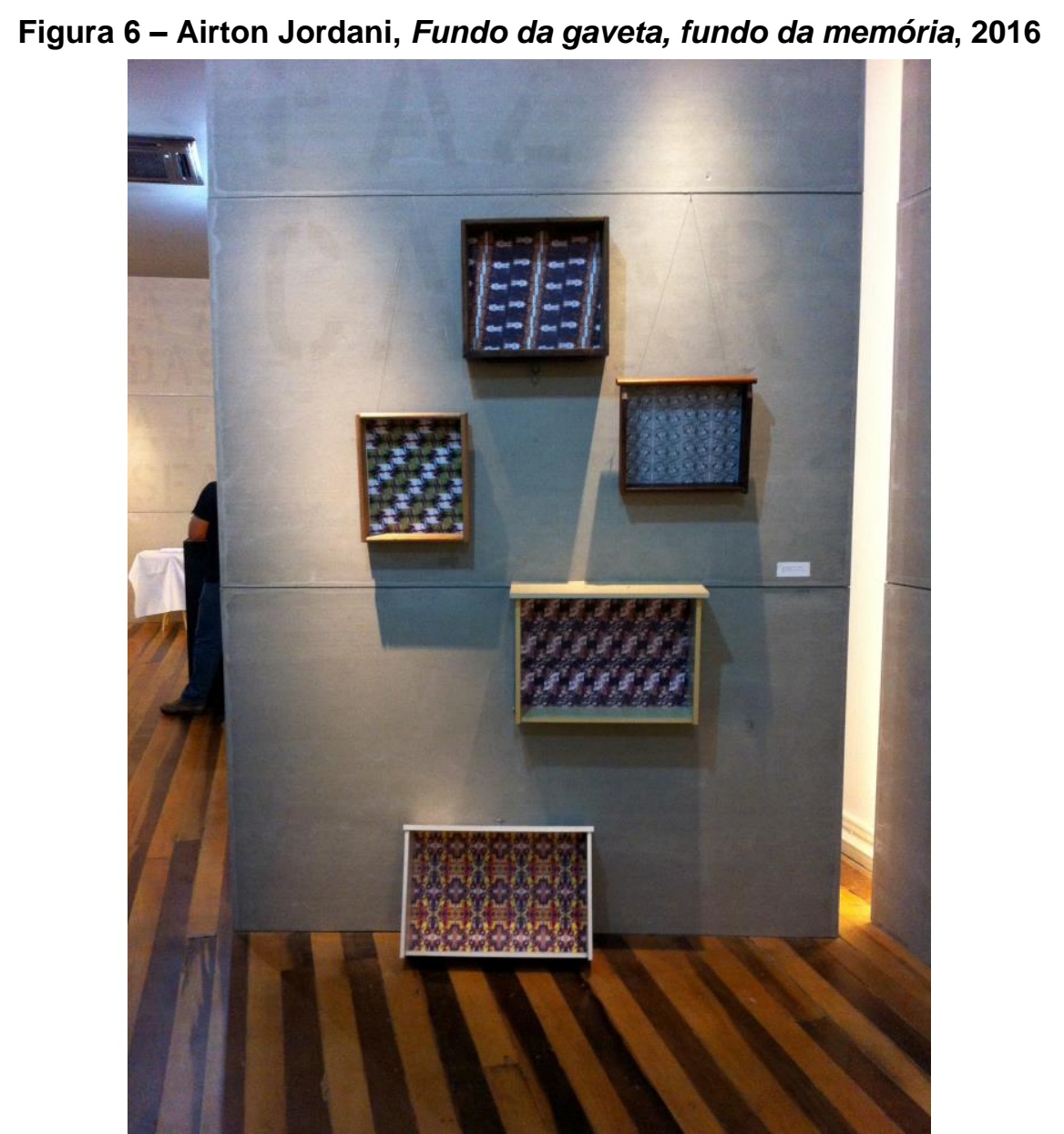

Fonte: Acervo do autor.

Quando Eduarda comentou que a gaveta continha um trabalho baseado em uma foto em que era retratada, afirmou lembrar-se deste dia. A partir disso, foi possível debater em torno de um novo tópico: as fotos ajudam a memória a permanecer viva ou distorcem a memória, sendo apenas um recorte descontextualizado daquele momento? Greicy afirmou nunca ter pensado nisso, mas concordou, acreditando ser esse um efeito colateral possível e bastante frequente.

Este primeiro momento da mediação foi encerrado com uma proposta de reflexão para o grupo - excetuando a criança -, sobre a possibilidade de existir, de fato, memórias reais e confiáveis ou se, como propõe Huyssen (2000), as memórias são sempre transitórias, não confiáveis e passíveis de esquecimento. 
Havia uma segunda parte da mediação, projetada para, justamente a partir deste gancho, aprofundar as questões teóricas envolvidas na concepção da mostra, no entanto, a avaliação foi de que o momento não seria propício em função do tempo disponível restante e do tempo já transcorrido.

Em um segundo momento, em um ambiente mais reservado, propício a um diálogo mais focado no tema, a mediação foi retomada, justamente a partir de um comentário de Eduarda a respeito da experiência da visita ao MESC e sobre a exposição [ gaveta(s) ], ressaltando a diferença da visita quando mediada. Em seu relato, lembrou que já tinha visto exposições de arte, mas estar conversando com o artista foi bem diferente, pois "ajudou a ver coisas que não sei se veria sozinha".

Susana relatou que percebera uma certa quantidade de eventos culturais falando de memória e ocorrendo quase que simultaneamente ${ }^{3}$ e questionou se 0 propósito da mostra [ gaveta(s) ] estava inserido de alguma forma em um "circuito" ou evento interligado. A partir deste gancho, foi possível demonstrar a memória como uma das preocupações culturais e políticas das sociedades ocidentais e apresentar alguns outros pontos elencados por Huyssen (2000) para refletir sobre o fenômeno da memória nos dias de hoje, entre eles o avanço do capitalismo de consumo e sua relação com a instabilidade e a crise de identidade do contemporâneo, a tênue relação entre lembrar e esquecer, a memória de uma sociedade e sua negociação no corpo social (crença, valores e rituais), a valorização dos espaços públicos de memória (museu, memorial, monumento), a memória como um agente de estabilização social em épocas de incerteza e, por fim, a memória (individual e social) como algo transitório, não confiável e passível de esquecimento, como já havia sido abordado, no final da primeira parte da mediação.

A segunda parte foi encerrada com o resgate da questão a respeito das memórias enquanto lugares reais e confiáveis e a emblemática frase do autor: "a

3 Uma breve pesquisa revelou que houve (apenas considerando Florianópolis) uma série de eventos relacionados à memória entre maio e junho de 2016: a mostra "Registros", de Joana Amarante na Fundação Badesc; a instalação interativa "Arquivo Provisório de Memórias", do Coletivo Nijinski, no Museu da Escola Catarinense (MESC) e a mostra "Memória em 4 tempos", na Fundação Badesc. 
permanência prometida pela pedra do monumento está sempre erguida sobre a areia movediça" (HUYSSEN, 2000, p. 68).

\section{Considerações Finais}

Este artigo foi estruturado de modo a mostrar, em um primeiro momento, a relação entre a disciplina Ação Educativa em Espaços Culturais e a mostra [gaveta(s)]. Foram evidenciados os conceitos de interação e de interface, de modo a ampliar o que o senso comum compreende - como algo vinculado às tecnologias digitais - para um fenômeno comunicacional que envolve tradução e mediação, pelo fato de que estes conceitos e fenômenos de comunicação estão diretamente implicados na experiência de vida. A seguir, buscou-se apresentar a relação da base teórica discutida em sala de aula com a proposta para a mostra: uma abordagem da memória como fenômeno sócio-histórico das sociedades contemporâneas. Por fim, apresentou-se a experiência da mediação, realizada com um grupo selecionado de pessoas, experiência que encerrou a proposta de vivenciar todas as etapas de uma exposição, da concepção à mediação, passando por toda a produção, museografia, comunicação e divulgação, conforme proposição inicial da disciplina.

É importante ressaltar que justamente durante a prática da mediação é que questões importantes - ligadas às leituras, discussões e reflexões oriundas da sala de aula - vieram à tona.

Quando Eduarda afirmou que a mediação "ajudou a ver coisas" que ela não veria sozinha, ratificou a proposta de mediação como interface proposta neste artigo. A tradução realizada através da mediação foi importante para que ela conseguisse ampliar suas percepções a partir de novas informações adquiridas e de seu esforço em conectá-las ao que estava sendo visto. Assim como quando Susana, a partir de sua própria observação do cotidiano, somada às discussões levantadas pela mostra através da mediação, percebeu o fenômeno contemporâneo de musealização das sociedades ocidentais, diretamente ligado ao momento em que se vive hoje nessas mesmas sociedades, isso para citar apenas dois exemplos vistos durante a mediação. 
A partir do que foi visto na disciplina e na experiência por ela propiciada, é possível afirmar que o envolvimento da ação educativa desde o planejamento até a mediação - passando por todas as etapas da produção - enseja que o processo de comunicação entre público e arte se torne muito mais efetivo, profícuo e, por que não, interativo.

\section{Referências}

ARGAN, Giulio Carlo. História da arte. In: ARGAN, Giulio Carlo; FAGIOLO, Maurizio. Guia de História da Arte. 2. ed. Lisboa: Estampa, 1994.

BONSIEPE, Gui. Do material ao digital. Florianópolis: LBDI, 1997.

FILATRO, Andrea. Design instrucional contextualizado. São Paulo: Editora Senac São Paulo, 2007.

FLEMING, Jennifer. Web Navigation: designing the user experience. Sebastopol/CA: O'Reilly Media, 1998.

FRANCO, Edgar Silveira. Hqtrônicas: do suporte papel à rede Internet. São Paulo: Annablume, 2004.

GROSSMANN, Martin. Museu como interface. In: GROSSMANN, Martin; MARIOTTI, Gilberto (Org.). Museum Art Today / Museu Arte Hoje. São Paulo: Hedra \& Forum Permanente, 2011. p. 193-221.

HUYSSEN, Andreas. Seduzidos pela memória: arquitetura, monumentos, mídia. Rio de Janeiro: Aeroplano, 2000.

JOHNSON, Steven. Cultura da interface: como o computador transforma nossa maneira de criar e comunicar. Rio de Janeiro: Jorge Zahar Ed. 2001.

LÉVY, Pierre. As tecnologias da inteligência: o futuro do pensamento na era da winformática. Rio de Janeiro: Ed. 34, 1993.

PRIBERAM. Dicionário da Língua Portuguesa. Disponível em: <http://www.priberam.pt/DLPO/interface>. Acesso em: 15 jul. 2016.

RAMALHO E OLIVEIRA, Sandra. [ gaveta(s) ]. In: [ gaveta(s) ]: convite da exposição. Florianópolis: UDESC e Museu da Escola Catarinense. 2016.

\section{Airton Jordani Jardim Filho}

Doutorando em Artes Visuais pelo Programa de Pós-Graduação em Artes Visuais - Centro de Artes, da Universidade do Estado de Santa Catarina (PPGAV/CEART/UDESC). Mestre em Design pelo Programa de Pós-Graduação em Design (PPGDesign/UDESC). Membro do grupo de pesquisa CNPq Núcleo de Estudos Semióticos e Transdisciplinares - (NEST/UDESC). Especialista em UX Design pela Universidade Federal de Santa Catarina (UFSC) e em Artes Visuais: Cultura e criação pelo Serviço Nacional de Aprendizagem Comercial (SENAC/EAD). Graduado em Licenciatura em Artes Visuais pela Universidade Federal do Rio Grande do Sul (UFRGS).

E-mail: airtonjordani@gmail.com

Currículo: http://lattes.cnpq.br/2542156617092220

Recebido em 04 de agosto de 2016 Aceito em 22 de novembro de 2016 